\section{Mortalidade materna por eclâmpsia}

\section{Eclampsia as a cause of maternal mortality}

Joe Luiz Vieira Garcia Novo 1

Reinaldo José Gianini 2

\begin{abstract}
1 Departamento de Cirurgia. Faculdade de Ciências Médicas e da Saúde, Sorocaba (PUC/SP). Praça Dr. José Ermírio de Moraes, 290. Bairro Vergueiro. CEP 18.030-230. Sorocaba, SP, Brasil. Email: joeluiznovo@hotmail.com

2 Departamento de Medicina. Faculdade de Ciências Médicas e da Saúde, Sorocaba (PUC/SP) Sorocaba, SP, Brasil.
\end{abstract}

\begin{abstract}
Objective: to assess the factors associated with maternal mortality resulting from eclampsia.

Methods: a retrospective cohort study reviewing the medical records of deliveries carried out at the Sorocaba Hospital Compound (between January 1995 and December 2005). The variables included were: year of delivery, social and demographic characteristics of mother, personal, family and obstetric history, characteristics of the pregnancy, delivery and puerperium, the kind care given, the evolution of the case, and the conditions for release from hospital. The statistical analysis involved the use of Fisher's exact test, the Pearson correlation and Poisson's multiple regression.
\end{abstract}

Results: 35973 deliveries were registered, 179 of which involved cases of eclampsia, 52 of them with serious complications, twenty-three resulting in a longer stay in intensive care and eight in death. The incidence of eclampsia decreased over the period (from $0.90 \%$ to $0.37 \% ; r=-0.746 ; p=0.008$ ), although the proportion of cases with serious complications remained unchanged $(0.25 \%$ compared with $0.17 \%$, $r=-0.45 ; p=0.162)$. The proportion of patients who died was larger among non-white patients ( $R R=9.10$; $C I 95 \%=1.83-45.23 ; p=0.007)$ and lower among those treated with magnesium sulfate $(R R=0.08$; CI95\%=0.02-0.35; $p=0.001$ ).

Conclusions: the incidence of eclampsia among deliveries performed at the Sorocaba Hospital Compound decreased, although the disease still represents a significant cause of maternal death in the region. This study shows that it is essential that early diagnostic measures and treatment of preeclampsia and eclampsia be perfected by the health care system. Key words Eclampsia, Maternal mortality, Magnesium sulfate

\section{Resumo}

Objetivo: analisar fatores associados à mortalidade materna causada por eclâmpsia.

Métodos: estudo de coorte retrospectivo revisando-se prontuários médicos dos partos assistidos no Conjunto Hospitalar de Sorocaba (janeiro/1995 a dezembro/2005). Variáveis pesquisadas: ano do parto, características sóciodemográficas maternas, antecedentes familiares, pessoais e obstétricos, características da gestação, parto, puerpério, atendimento realizado, evolução e condições de alta. A análise estatística incluiu teste exato de Fisher, correlação de Pearson, e regressão múltipla de Poisson.

Resultados: registraram-se 35.973 partos, 179 casos de eclâmpsia, 52 com sérias complicações, 23 com maior permanência no tratamento intensivo e 8 evoluíram para óbito. A proporção de eclâmpsia decresceu no periodo $(0,90 \%$ para $0,37 \% ; r=-0,746$; $p=0,008)$, mas mantendo a proporção de casos com sérias complicações $(0,25 \%$ para $0,17 \%, r=-0,45$; $p=0,162)$. A proporção de óbitos foi maior entre pacientes não brancas (RR=9,10; IC $95 \%=1,83$ 45,23; $p=0,007)$ e menor entre as tratadas com sulfato de magnésio $(R R=0,08 ; I C 95 \%=0,02-0,35$; $p=0,001)$.

Conclusões: reduziu-se a proporção de eclâmpsia entre os partos assistidos no Conjunto Hospitalar de Sorocaba, porém, a eclâmpsia continua sendo importante causa de óbito materno na região. Este estudo revela que é fundamental o aperfeiçoamento das medidas de diagnóstico precoce e tratamento da préeclâmpsia e eclâmpsia pela rede de atenção à saúde. Palavras-chave Eclâmpsia, Mortalidade materna, Sulfato de magnésio 


\section{Introdução}

A doença hipertensiva específica da gravidez ou préeclâmpsia, é a entidade mais importante daquelas que se manifestam ou se agravam durante a evolução do ciclo grávido puerperal. Associam-se a ela altos índices de morbiletalidade materna e fetal.1,2

Sendo doença exclusiva da segunda metade da gravidez, principalmente após 24 semanas, sua ocorrência é rara antes de 20 semanas (toxemia precoce), quando se associa à neoplasia trofoblástica gestacional e às síndromes antifosfolípides. ${ }^{1}$

Eclâmpsia é a manifestação convulsiva ou comatosa da pré-eclâmpsia, quer de forma isolada ou associada à hipertensão arterial materna preexistente. Trata-se de uma intercorrência emergencial com distribuição universal, estando comprovada sua incidência crescente, apesar das tentativas e alterações instituídas para o seu controle.3,4

Estima-se, nos países desenvolvidos, incidência em torno de 1:330 partos, enquanto no Brasil, em hospitais universitários, ocorre aproximadamente em $1 \%$ das gestações. ${ }^{1}$ As complicações dependem de uma série de variáveis diretamente ligadas ao binômio materno-fetal, bem como da qualidade assistencial, seja nos centros primários, secundários ou terciários, nos quais se dispõe de terapia intensiva. 5

A eclâmpsia é a forma mais grave dos distúrbios hipertensivos, que continuam presentes entre as complicações obstétricas mais importantes. 1 Apresenta evolução insidiosa e grave em proporções mundiais, acompanhada de elevada morbiletalidade materno-fetal, principalmente em países em desenvolvimento. 5 Segundo alguns autores a eclâmpsia seria responsável por aproximadamente 50.000 mortes maternas anuais. ${ }^{6}$

Os óbitos maternos causados por eclâmpsia são decorrentes de hemorragia cerebral, 7 edema agudo de pulmão, insuficiência renal aguda, insuficiência hepática com ou sem coagulação intravascular disseminada, complicações respiratórias secundárias à broncoaspiração de conteúdo gástrico, que soem acontecer em forma isolada ou associados entre si.

A prevenção da eclâmpsia poderá ser alcançada mediante uma efetiva assistência pré-natal na atenção primária, complementada pela atenção secundária aos grupos de risco. 5,8 Até que se tenha diagnóstico diferencial, a convulsão em gestação avançada deve ser considerada como diagnóstico de eclâmpsia, e os melhores resultados maternos e perinatais são obtidos pela adoção de protocolos padronizados em serviços de nível terciário. Orientase a conduta assistencial para medidas gerais de suporte cardiorrespiratório, terapia anticonvulsivante, tratamento anti-hipertensivo e conduta obstétrica resolutiva. ${ }^{1}$

Os hospitais de referência, por cumprirem papel definido na rede assistencial de atendimento aos casos mais complexos e graves, acabam sendo locais sentinelas da ocorrência de eventos desta natureza, podendo oferecer dados cruciais que contribua para a resolução do problema.

Diante da relevância da eclâmpsia julgou-se oportuna a realização do presente estudo, a fim de contribuir para a descrição de sua ocorrência e para a análise dos fatores associados e das suas possíveis suas consequências. ${ }^{9}$

\section{Métodos}

Realizou-se um estudo de coorte com base na análise retrospectiva dos prontuários de todas as gestantes, parturientes e puérperas, nas faixas etárias de 10 a 49 anos, atendidas no Conjunto Hospitalar de Sorocaba, Estado de São Paulo, durante o período de $01 / 01 / 1995$ a $31 / 12 / 2005$, assistidas na maternidade e unidades de emergência. Destes prontuários foram selecionados para análise subsequente aqueles com diagnóstico de eclâmpsia. O estudo teve início após a aprovação pelo Comitê de Ética em Pesquisa da Faculdade de Ciências Médicas e da Saúde, e do Conjunto Hospitalar de Sorocaba, respeitando-se as normas da Declaração de Helsinque e da resolução $n^{\circ}$. 196/96 do Conselho Nacional de Saúde, para pesquisa em seres humanos.

As pacientes foram definidas clinicamente observando-se o modelo do Comitê Americano de Ginecologia e Obstetrícia, como sendo a associação de quadro convulsivo tônico-clônico ou comatoso, aos grupos de pré-eclâmpsia, isoladamente, ou, ainda, sobreposta à hipertensão arterial crônica materna. 10

Considerou-se como pré-eclâmpsia o surgimento da hipertensão na segunda metade da gravidez, associada à proteinúria de $\geq 300 \mathrm{mg} / 24$ horas, com remissão no evoluir do puerpério. A forma leve foi caracterizada, quando os níveis pressóricos estivessem até $160 / 110 \mathrm{mmHg}$, e proteinúria abaixo de $2 \mathrm{~g} / 24$ horas. A forma grave classificou-se na presença de pressão arterial diastólica superior a 110 $\mathrm{mmHg}$, associando-se a proteinúria $\geq 2 \mathrm{~g} / 24$ horas, oligúria (diurese $\leq 40 \mathrm{~mL} / 24$ horas), dor epigástrica em barra, escotomas, cefaléia nucal, turvação visual, plaquetas $\leq 100.000 \mathrm{~mm}^{3}$, bilirrubinas $\geq 1,2 \mathrm{mg} \%$, creatinina $\geq 1,2 \mathrm{mg} \%$, transaminases $\geq 72 \mathrm{U}$ e/ou desidrogenase láctica $\geq 600 \mathrm{U}$. Considerou-se préeclâmpsia sobreposta, quando em pacientes com 
hipertensão arterial existente desde a primeira metade da gravidez, e persistente no puerpério tardio. 11

A hipertensão arterial foi definida pela presença, desde o início da gestação, de níveis tensionais iguais ou superiores a $140 / 90 \mathrm{mmHg}$, confirmados após seis horas de observação. Foram incluídas pacientes com idade gestacional mínima de 20 semanas completas ou com nascituros com peso igual ou superior a $500 \mathrm{~g}$. A idade gestacional baseou-se na data da última menstruação, auxiliada pela medida da altura uterina, e confirmada por ultrassonografia. ${ }^{1}$

Os dados referentes ao tratamento com sulfato de magnésio se referem às pacientes com quadro convulsivo, ou coma, que foram medicadas com sulfato de magnésio heptahidratado, com dose inicial de $4 \mathrm{~g}$ em via endovenosa, durante cerca de 15 minutos (dose de ataque), salvo se vigentes contraindicações como oligúria e/ou manifestações de toxicidade magnesiana (depressão respiratória ou abolição dos reflexos tendinosos profundos). O controle desse tratamento continuou com $1 \mathrm{~g} /$ hora em via venosa, como dose de manutenção, até aproximadamente 24 horas após a estabilização clínica não convulsiva. 11

$\mathrm{O}$ tratamento complementar se referiu à hipertensão ou crise hipertensiva, que não cedeu após cessarem as crises convulsivas, e foram medicadas com hidralazina pela via endovenosa em bolo (5 mg). A dose repetiu-se a cada $15-20$ minutos, até que a pressão arterial diastólica diminuiu e se estabilizou durante 12 a 24 horas em níveis diastólicos pressóricos cerca de 20-30\% abaixo da medida inicial. Os diuréticos e cardiotônicos foram utilizados por via venosa, na vigência de edema agudo de pulmão. ${ }^{12}$

Nas pacientes com idade gestacional igual ou superior a 34 semanas, inicialmente foram tratadas as urgências convulsivas, e realizado o controle da pressão sanguínea, para estabilização das condições maternas. A seguir iniciava-se a tentativa de resolução da gravidez (vias vaginal ou abdominal, indicadas pelas condições obstétricas). O procedimento anestésico preferencialmente direcionava-se para anestesia de condução (raquídea ou peridural). Nos casos de distúrbios de coagulação, e simultaneidade de convulsões maternas ou sofrimento fetal agudo, optou-se pelo tiopental sódico (narcoanestesia). ${ }^{1} \mathrm{O}$ controle puerperal realizou-se inicialmente em Unidade de Terapia Intensiva. Após estabilização clínica procedeu-se o encaminhamento para a enfermaria. As pacientes eclâmpticas eram sempre assistidas por equipes multidisciplinares, e de acordo com a sua evolução. ${ }^{1,11}$

Para cada paciente preencheu-se uma observação detalhada e confidencial de seus dados gerais, antecedentes familiares, hábitos e vícios (tabagismo, alcoolismo e drogas ilícitas), antecedentes pessoais, diagnóstico obstétrico pregresso e atual, assistência pré-natal, internação, atendimento, número de convulsões, medicamentos, classificação da eclâmpsia (gestacional, intraparto, puerperal), tipo de parto (normal, fórcipe, cesáreo), anestesia utilizada, indicações e/ou complicações cirúrgicas (imediatas e tardias), alta materna, e óbito materno. No evento da internação anotaram-se idade gestacional (calculada pela data da última menstruação ou exame ultrassonográfico), pressão arterial diastólica na admissão e estado geral materno (bom: condições gerais conservadas; regular: paciente em pré-choque e consciente; grave: chocada, convulsionando ou comatosa).

Quanto ao atendimento, classificou-se como primário ou secundário. No atendimento primário, a paciente veio diretamente ao hospital sem qualquer medicação prévia. No atendimento secundário, a paciente veio encaminhada e já medicada por outro serviço. Foi anotado o número de convulsões observadas em cada paciente.

As complicações maternas foram acompanhadas em enfermaria ou permanência na Unidade de Terapia Intensiva, levando à recuperação e alta materna, ou à ocorrência do óbito materno.

Para a análise estatística, os dados foram registrados em protocolo individualizado, para posterior elaboração do banco de dados informatizado com digitação em planilha Excel ${ }^{\circledR}$ e transferido para o programa $\mathrm{STATA}^{\circledR}$, com o qual se procedeu ao tratamento estatístico. 13

Foram estudadas a distribuição das frequências absoluta e relativa das categorias das variáveis pesquisadas e sua associação com complicações clínicas e mortalidade. As variáveis com $10 \%$ ou mais de perda de informação foram descartadas.

Utilizou-se o teste exato de Fisher bicaudal para o cálculo da significância estatística da associação. Considerou-se significante $p<0,05$. Calculou-se o risco relativo, para verificar a magnitude do efeito da associação, com intervalos de $95 \%$ de confiança. Para as variáveis que apresentaram $p<0,20$ nesta primeira análise, empregou-se a regressão múltipla de Poisson. Manteve-se no modelo final apenas as variáveis com $p<0,05$. Além disto, empregou-se a correlação de Pearson para verificar a tendência da proporção de partos com eclâmpsia no período 19952005.13 


\section{Resultados}

As variáveis escolaridade $(37,4 \%)$, procedência $(15,1 \%)$, e estado civil $(29,6 \%)$ foram descartadas das análises por apresentarem perda de informação excessiva.

A variável pré-natal foi excluída da análise de associações (16,8\% de perda). Não realizaram prénatal 18 pacientes, 80 pacientes referiram menos de cinco consultas de pré-natal, e 51 pacientes referiram assistência pré-natal adequada (seis ou mais consultas).

As variáveis antecedentes familiares de malformações, outros antecedentes familiares, neomortos e natimortos pregressos não entraram na análise por causa da pequena frequência $(\mathrm{n}<5)$, pois resultaram em poder estatístico insuficiente.

Só foi possível analisar a associação de tabagismo com complicações maternas, pois todos os óbitos foram registrados como de não fumantes.

Apresentaram história pregressa de préeclâmpsia oito pacientes $(4,5 \%)$; e de eclâmpsia, três pacientes $(1,7 \%)$.

A conduta inicial foi expectante em 33 casos $(18,4 \%)$, o tipo de parto foi vaginal em 33 casos, tendo sido induzidos 31 (17,3\%).

Durante o período estudado assistiram-se no Conjunto Hospitalar de Sorocaba a 35.973 partos, com 179 casos de eclâmpsia (proporção de 0,5\%). Em 1995 esta proporção foi maior $(0,90 \% ; 22 / 2432)$, sendo menor em 2005 (0,37\%; 9/2395), verificandose redução significante no período $(\mathrm{r}=-0,746$; $p=0,008)$. Entre estes casos de eclâmpsia, 52 evoluíram com sérias complicações, sendo $0,25 \%$ (6/2432) em 1995 e $0,17 \%$ (4/2395) em 2005, não se verificando correlação significante $(r=-0,45$; $p=0,162$ ) (Figura 1).

Figura 1

Proporção de casos de eclâmpsia entre os partos assistidos pelo Conjunto Hospitalar de Sorocaba. Período de $1995-2005$

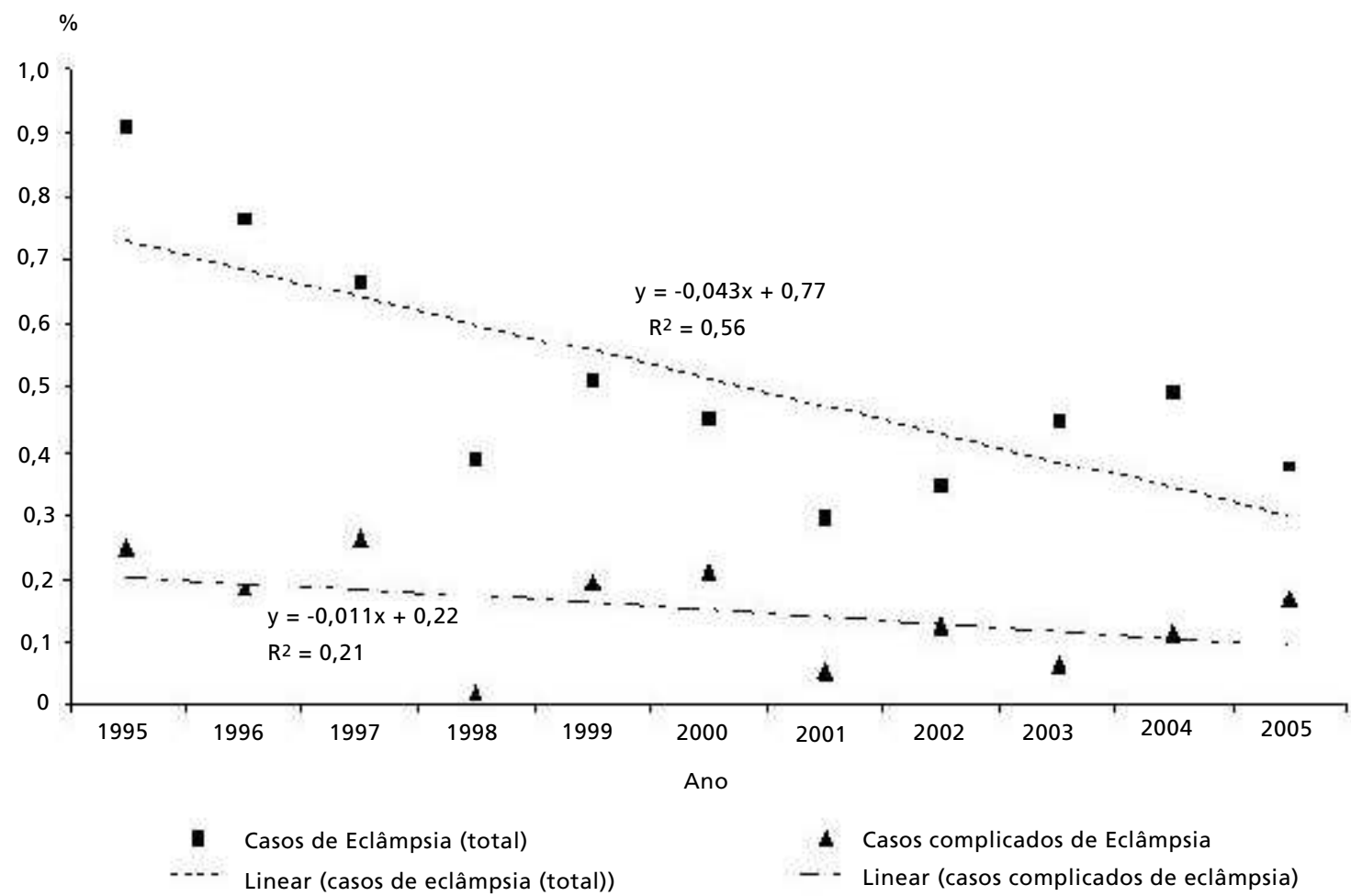


Ocorreram oito óbitos entre os 179 casos de eclâmpsia (4,46\%), o que significou, nesta amostra de 35.973 partos, uma mortalidade específica por eclâmpsia de 22,24 óbitos para 100.000 partos. No modelo final da regressão múltipla houve associação significante de óbito por eclâmpsia com cor, e tratamento com sulfato de magnésio. As pardas ou negras apresentaram maior risco de óbito $(\mathrm{RR}=9,10$; IC95\%=1,83-45,23; $p=0,007)$, e as tratadas com sulfato de magnésio tiveram menor risco de óbito $(\mathrm{RR}=0,08 ; \quad \mathrm{IC} 95 \%=0,02-0,35 ; \quad p=0,001) . \quad$ Foi excluída desta análise a variável estado materno na admissão porque era a situação de todas as pacientes que evoluíram para óbito (Tabela 1).

Na Tabela 2 observa-se ainda que, entre os óbitos maternos, nenhum recebeu assistência pré-natal adequada (cinco ou mais consultas), e 62,5\% (5/8) estavam em idade gestacional passível de interrupção ( $\geq 30$ semanas).

As complicações clínicas mais frequentes foram: coma cerebral (7), coagulação intravascular disseminada (5), parada cardiorrespiratória (4) e insuficiência renal (3). As variáveis associadas significantemente às complicações no modelo final de regressão múltipla foram: mau estado geral na admissão ( $\mathrm{RR}=2,36$; IC95\%=1,06-5,24; $p=0,035)$, pressão arterial diastólica na admissão $\geq 110 \mathrm{mmHg}$ $(\mathrm{RR}=1,86$; IC95\% $=1,01-3,44 ; p=0,047)$, e número de convulsões $\geq 4(\mathrm{RR}=2,39$; IC95\%=1,16-4,91; $p=0,018$ ) (Tabela 3 ).

Tabela 1

Análise da associação de determinados fatores pesquisados com os óbitos por eclâmpsia. Conjunto Hospitalar de Sorocaba 1995-2005.

\begin{tabular}{|c|c|c|c|c|c|c|c|c|}
\hline \multirow[t]{2}{*}{ Variável } & \multicolumn{2}{|c|}{ Óbito } & \multirow[t]{2}{*}{$\mathbf{R R}$} & \multirow[t]{2}{*}{ IC95\% Bruto } & \multirow[t]{2}{*}{$p$} & \multirow[t]{2}{*}{$\mathbf{R R}^{*}$} & \multirow[t]{2}{*}{ IC95\% * Ajustado } & \multirow[t]{2}{*}{$p^{*}$} \\
\hline & Sim & Não & & & & & & \\
\hline Idade (anos) & & & & & 0,53 & & & \\
\hline$<21$ & 5 & 87 & 1,58 & $0,38-6,59$ & & & & \\
\hline$\geq 21$ & 3 & 84 & 1,00 & & & & & \\
\hline Cor & & & & & 0,005 & & & 0,007 \\
\hline Branca & 2 & 128 & 1,00 & & & & & \\
\hline Parda ou negra & 6 & 33 & 10,00 & $2,02-49,6$ & & 9,10 & $1,83-45,23$ & \\
\hline \multicolumn{9}{|c|}{ Antecedentes Familiares } \\
\hline de HAS & & & & & 0,70 & & & \\
\hline Sim & 2 & 54 & 0,73 & $0,15-3,63$ & & & & \\
\hline Não & 6 & 117 & 1,00 & & & & & \\
\hline \multicolumn{9}{|l|}{ Antecedentes familiares } \\
\hline de diabetes & & & & & 0,99 & & & \\
\hline Sim & 1 & 21 & 1,01 & $0,13-8,29$ & & & & \\
\hline Não & 7 & 150 & 1,00 & & & & & \\
\hline \multicolumn{9}{|l|}{ Antecedentes familiares } \\
\hline de gemelares & & & & & 0,86 & & & \\
\hline Sim & 1 & 18 & 1,20 & $0,15-9,78$ & & & & \\
\hline Não & 7 & 153 & 1,00 & & & & & \\
\hline Gestações pregressas & & & & & 0,30 & & & \\
\hline Sim & 4 & 54 & 1,00 & & & & & \\
\hline Não & 4 & 116 & 0,48 & $0,12-1,93$ & & & & \\
\hline Partos pregressos & & & & & 0,22 & & & \\
\hline Sim & 4 & 49 & 2,36 & $0,59-9,43$ & & & & \\
\hline Não & 4 & 121 & 1,00 & & & & & \\
\hline
\end{tabular}

continua 


\section{Tabela 1}

Análise da associação de determinados fatores pesquisados com os óbitos por eclâmpsia. Conjunto Hospitalar de Sorocaba 1995-2005

\begin{tabular}{|c|c|c|c|c|c|c|c|c|}
\hline \multirow[t]{2}{*}{ Variável } & \multicolumn{2}{|c|}{ Óbito } & \multirow[t]{2}{*}{$\mathbf{R R}$} & \multirow[t]{2}{*}{ IC95\% Bruto } & \multirow[t]{2}{*}{$p$} & \multirow[t]{2}{*}{$\mathbf{R R}^{*}$} & \multirow[t]{2}{*}{ IC95\% * Ajustado } & \multirow[t]{2}{*}{$p^{*}$} \\
\hline & $\operatorname{Sim}$ & Não & & & & & & \\
\hline Abortos pregressos & & & & & 0,29 & & & \\
\hline Sim & 2 & 20 & 2,36 & $0,48-11,7$ & & & & \\
\hline Não & 6 & 150 & 1,00 & & & & & \\
\hline Nativivos pregressos & & & & & 0,18 & & & \\
\hline Sim & 4 & 46 & 2,56 & $0,64-10,2$ & & & & \\
\hline Não & 4 & 124 & 1,00 & & & & & \\
\hline Idade gestacional (semanas) & & & & & 0,40 & & & \\
\hline$<35$ & 3 & 91 & 0,93 & $0,78-1,10$ & & & & \\
\hline$\geq 35$ & 3 & 72 & 1,00 & & & & & \\
\hline \multicolumn{9}{|l|}{ Pressão arterial diastólica } \\
\hline na admissão & & & & & 0,48 & & & \\
\hline$<110$ & 5 & 98 & 1,79 & $0,35-9,26$ & & & & \\
\hline$\geq 110$ & 2 & 72 & 1,00 & & & & & \\
\hline Atendimento & & & & & 0,63 & & & \\
\hline Primário & 2 & 58 & 0,67 & $0,14-3,72$ & & & & \\
\hline Secundário & 6 & 113 & 1,00 & & & & & \\
\hline Número de convulsões & & & & & 0,09 & & & \\
\hline$\geq 4$ & 2 & 12 & 3,92 & $0,79-19,5$ & & & & \\
\hline$<4$ & 6 & 159 & 1,00 & & & & & \\
\hline \multicolumn{9}{|l|}{ Tratamento com sulfato } \\
\hline de magnésio & & & & & $<0,001$ & & & 0,001 \\
\hline Sim & 5 & 167 & 0,07 & $0,02-0,28$ & & 0,08 & $0,002-0,35$ & \\
\hline Não & 3 & 4 & 1,00 & & & & & \\
\hline Classe gestacional & & & & & 0,57 & & & \\
\hline GE & 7 & 135 & 1,82 & $0,22-14,8$ & & & & \\
\hline IP ou PU & 1 & 36 & 1,00 & & & & & \\
\hline
\end{tabular}

HAS= hipertensão arterial sistêmica; GE=gestacional; IP=intraparto; PU=puerperal; *ajustados tratamento com sulfato de magnésio e cor entre si; $\mathrm{R}^{2}$ do modelo=0,27.

Tabela 2

Descrição das características principais dos óbitos maternos por eclâmpsia. Conjunto Hospitalar de Sorocaba $1995-2005$.

\begin{tabular}{|c|c|c|c|c|c|c|c|c|c|}
\hline Ano & Cor & Paridade & Pré-natal Ic & $\begin{array}{l}\text { Idade gestacional } \\
\text { (semanas) }\end{array}$ & Fase CGP & $\begin{array}{c}\text { PAD admissão } \\
\mathrm{mmHg}\end{array}$ & Atendimento & Sulfato $\mathrm{Mg}$ & $\begin{array}{c}\text { Complicações } \\
\text { maternas }\end{array}$ \\
\hline 1995 & parda & $2 g, 2 p$ & não & ignorada & puérpera & 140 & secundário & não & $\begin{array}{l}\text { IRA; esteatose } \\
\text { hepática }\end{array}$ \\
\hline 1995 & branca & $1 \mathrm{~g}, 0 \mathrm{p}$ & ignorado & ignorada & gestante & 130 & secundário & $\operatorname{sim}$ & Coma; PCR \\
\hline 1995 & branca & $1 g, 0 p$ & inadequado & 37 & gestante & 100 & secundário & não & Coma; PCR \\
\hline 1995 & parda & $3 g, 2 p$ & ignorado & 40 & gestante & ausente & secundário & não & $\begin{array}{l}\text { PCR; cesárea } \\
\text { pós-morte }\end{array}$ \\
\hline
\end{tabular}


Tabela 2

Descrição das características principais dos óbitos maternos por eclâmpsia. Conjunto Hospitalar de Sorocaba 1995-2005.

\begin{tabular}{|c|c|c|c|c|c|c|c|c|c|}
\hline Ano & Cor & Paridade & Pré-natal Ic & $\begin{array}{l}\text { Idade gestacional } \\
\text { (semanas) }\end{array}$ & Fase CGP & $\begin{array}{c}\text { PAD admissão } \\
\mathrm{mmHg}\end{array}$ & Atendimento & Sulfato $\mathrm{Mg}$ & $\begin{array}{c}\text { Complicações } \\
\text { maternas }\end{array}$ \\
\hline 1997 & negra & $4 g, 2 p$ & não & 22 & gestante & 100 & secundário & $\operatorname{sim}$ & $\begin{array}{c}\text { HELLP; CIVD; } \\
\text { SARA; IRA }\end{array}$ \\
\hline 1997 & negra & $1 g, 0 p$ & inadequado & 36 & gestante & 120 & primário & $\operatorname{sim}$ & $\begin{array}{c}\text { Edema agudo de } \\
\text { pulmão }\end{array}$ \\
\hline 1997 & parda & $5 g, 3 p$ & inadequado & 32 & gestante & ignorado & primário & $\operatorname{sim}$ & HELLP;CIVD;Coma \\
\hline 2005 & negra & $1 \mathrm{~g}, 0 \mathrm{p}$ & ignorado & 30 & gestante & 110 & secundário & $\operatorname{sim}$ & Coma; PCR \\
\hline
\end{tabular}

$\overline{C G P}=$ ciclo grávido puerperal ; $P A D=$ pressão arterial diastólica; $M g=$ magnésio; IRA= insuficiência renal aguda; $P C R=$ parada cardiorrespiratória; HELLP= hemólise, elevação das enzimas hepáticas, plaquetopenia; CIVD= coagulação intravascular disseminada; SARA= síndrome de aspiração respiratória aguda). Todas as pacientes que evoluíram para óbito apresentavam mal estado geral na admissão.

Tabela 3

Fatores pesquisados associados no modelo final da regressão múltipla com a ocorrência de complicações clínicas maternas. Conjunto Hospitalar de Sorocaba 1995-2005.

\begin{tabular}{|c|c|c|c|c|c|c|c|c|}
\hline \multirow[t]{2}{*}{ Variável } & \multicolumn{2}{|c|}{ Complicações } & \multirow[t]{2}{*}{$\mathbf{R R}$} & \multirow[t]{2}{*}{ IC95\% Bruto } & \multirow[t]{2}{*}{$p$} & \multirow[t]{2}{*}{$\mathbf{R R}^{*}$} & \multirow[t]{2}{*}{ IC95\%* Ajustado } & \multirow[t]{2}{*}{$p^{*}$} \\
\hline & Sim & Não & & & & & & \\
\hline \multicolumn{9}{|c|}{ Mau estado geral na admissão } \\
\hline Sim & 46 & 80 & 2,60 & $1,17-5,77$ & 0,02 & 2,36 & $1,06-5,24$ & 0,04 \\
\hline Não & 7 & 44 & 1,00 & & & & & \\
\hline \multicolumn{9}{|c|}{ Pressão arterial diastólica } \\
\hline 110 ou maior & 38 & 63 & 1,99 & $1,08-3,67$ & 0,03 & 1,86 & $1,01-3,44$ & 0,05 \\
\hline$<110$ & 14 & 60 & 1,00 & & & & & \\
\hline \multicolumn{9}{|c|}{ Número de convulsões } \\
\hline 4 ou mais & 9 & 5 & 2,44 & $1,19-5,00$ & 0,02 & 2,39 & $1,16-4,91$ & 0,02 \\
\hline$<4$ & 44 & 119 & 1,00 & & & & & \\
\hline
\end{tabular}

*ajustados entre si; $R^{2}=0,04$.

\section{Discussão}

Os resultados desta avaliação revelaram que a eclâmpsia representa relevante doença obstétrica no Conjunto Hospitalar de Sorocaba, característica presente nos países em desenvolvimento, nos quais as condições assistenciais estão aquém das necessárias para programas preventivos.14-16 A proporção de $0,5 \%$ encontrada na casuística significa aproximadamente um caso de eclâmpsia a cada 200 partos. Esse achado representou valores superiores aos encontrados em países desenvolvidos (um caso de eclâmpsia a cada 330 partos), em virtude desses países investirem e atuarem em programas preven- tivos, oferecendo à população melhores condições assistenciais. 1,5

Apesar de a eclâmpsia ser uma forma grave da pré-eclâmpsia, em geral, com evolução insidiosa, permite ações nos serviços de atenção à assistência pré-natal e à parturição, sendo possível reduzir-se de maneira substancial a morbiletalidade materna e fetal. Entretanto, para a assistência pré-natal ser efetiva, é necessário que se inicie ainda no primeiro trimestre de gravidez e haja boa adesão da gestante, de modo que sejam realizadas no mínimo cinco consultas. $1,5,17$ 
É nítida a informação nesta pesquisa sobre a gravidade do estado geral materno na admissão hospitalar, como foi observado na Tabela 1 (127/179; 71\%). Concorreram para essa situação atendimentos em unidades primárias ou secundárias com esquemas incorretos de prevenção, tratamentos inadequados das convulsões e equívocos na utilização de anti-hipertensivos para as emergências hipertensivas maternas. Observaram-se como intervenientes, ainda, a demora do transporte e a falta de integração entre os centros assistenciais primários, secundários e terciários, ${ }^{6}$ além da dificuldade de acesso das usuárias a esses centros. 18

Os resultados desvelaram maiores proporções de óbitos em pacientes não brancas, confirmando achados de outros autores que os relacionam a fatores socioeconômicos desfavoráveis e hereditariedade.1,19 Apesar de outras pesquisas citarem a maior suscetibilidade de eclâmpsia em primíparas, 1,5 observa-se nesta amostra proporção significativa de multíparas, fato possivelmente explicado pela préexistência de hipertensão arterial subclínica nesse grupo, o que poderia explicar também os agravos nas pacientes com níveis arteriais diastólicos $\geq 110$ mmHg. 14

A vasoconstrição arteriolar, em especial a cerebral, favorece a presença de múltiplas zonas de hemorragias promovidas pela ruptura do endotélio vascular, 7 causando vasoconstrição persistente, trombose, hipóxia cerebral, mais frequentes nos lobos occipitais.20-22 Em geral, geram-se maiores números de áreas lesadas, de convulsões, e consequente piora do prognóstico materno. ${ }^{1} \mathrm{O}$ sulfato de magnésio tem reconhecida a sua superioridade em relação aos demais fármacos, conhecidos no controle e prevenção da recidiva de convulsões na eclâmpsia.22,23 A sua atuação seria por bloqueio neuronal dos canais de cálcio, indução da produção e liberação de prostaciclina, promovendo vasodilatação local, atenuando agonistas, reduzindo a isquemia cerebral. 23

Em nossa casuística notou-se, também, que as proporções de pacientes eclâmpticas foram declinando significantemente de 1995 a 2005. Tais fatos podem ser creditados às estratégias de ação do Ministério da Saúde na assistência pré-natal, lançando objetivos de definição para um modelo nacional normatizado para as assistências relacionadas, associando esforços para a melhora dos resultados observados. O modelo proposto, denominado Programa de Humanização do Pré-Natal, incluiu modelos assistenciais atuantes e recomendados em países desenvolvidos, em práticas prénatais às suas bases conceituais. 24
Associa-se ao programa educativo anterior uma atenção pré-natal de maior extensão, com a consequente possibilidade de promover, mesmo em ambientes primários ou secundários, manejos intervencionistas mais seguros em relação às mães e seus conceptos, o que evitaria a pré-eclâmpsia e a eclâmpsia numa boa proporção de pacientes. 5,25 Entretanto, os presentes resultados sugerem que existem falhas naqueles casos em que a préeclâmpsia e a eclâmpsia não foram evitadas, e se referem ao diagnóstico precoce, tratamento imediato e limitação de incapacidades ou óbitos. ${ }^{5}$

À semelhança de outros estudos, para a redução da mortalidade materna na eclâmpsia, enfatiza-se, ainda, a importância da atuação educativa dos Comitês de Mortalidade Materna e Perinatal.17 São relevantes os controles de qualidade hospitalar, 26 e o treino periódico dos centros de atendimentos primários e secundários. 25,27 É obrigação do Estado garantir assistência integral à saúde. Há necessidade urgente de aplicação plena dos programas de saúde destinados à mulher brasileira. 1,6

Devem ser destacadas as limitações do presente estudo que se referem à: amostra estudada que é representativa da clientela de um serviço público terciário e não da população geral, representatividade que varia ao longo do tempo; perda de informação em virtude das falhas de registro em prontuários e à coleta de dados extra-hospitalares dependentes da memória das pacientes ou de seus respectivos informantes; possibilidade de efeito confundimento residual mesmo tendo sido empregado o método mais adequado, pois, o poder estatístico do modelo é reduzido, escapando variáveis já no modelo inicial e ficando no modelo final apenas as mais fortemente associadas, com um baixo poder explicativo dos modelos finais $\left(\mathrm{R}^{2}\right)$; e imprecisão das medidas em virtude do pequeno número de óbitos incluídos no estudo.

Conclui-se que, apesar da redução observada na proporção de casos de eclâmpsia entre os partos assistidos pelo Conjunto Hospitalar de Sorocaba no período estudado, a eclâmpsia continua sendo importante causa de óbito materno na região. Esse estudo revela que é fundamental aperfeiçoar as medidas de prevenção secundária da pré-eclâmpsia e da eclâmpsia pela rede de atenção à saúde, dirigindoas aos grupos mais vulneráveis da população.

\section{Agradecimentos}

Agradecemos ao corpo clínico da maternidade do Conjunto Hospitalar de Sorocaba, pela oportunidade de realizar este trabalho. 


\section{Referências}

1. Neme B, Alves EA. Obstetrícia Básica. In: Neme B, editor. Doença hipertensiva específica da gestação: eclâmpsia. 3 ed. São Paulo: Sarvier; 2006. p. 284-91.

2. World Health Organization. The world health report: make every mother and child count. Geneva; 2005.

3. Phupong V, Dejthevaporn T. Predicting risks of preeclâmpsia and small for gestational age infant by uterine artery Doppler. Hypertens Pregnancy. 2008; 27: 387-95.

4. Roncalia N, Crippa I, Locatelli A, Cameroni I, Orsenigo F, Vergani P, Ghidini A. Prediction of superimposed preeclampsia using uterine artery doppler velocimetry in women with chronic hypertension. Prenat Diagn. 2008; 28: 710-4.

5. Castro AM, Trujillo AMB. Incidencia y aspectos clínicos relacionados com la eclampsia. Rev Colomb Obstet Ginecol. 2002; 53: 279-90.

6. Kullima AA, Kawuwa MB, Audu BA, Usman H, Geidam AD. A 5-year review of maternal mortality associated with eclampsia in as tertiary institution of northern Nigéria. Annal Afric Med. 2009; 8: 81-4.

7. Davie CA, O'Brien P. Stroke and pregnancy. J Neurol Neurosurg Psyquiatry. 2008; 79: 240-5.

8. Meads CA, Cnossen JS, Meher S, Juarez-Garcia A, ter Riet G, Duley, Roberts TE, Mol BW, van der Post JA, Leeflang MM, Barton PM, Hyde CJ, Gupta JK, Khan KS. Methods of prediction and prevention of preeclampsia: systematic reviews of accuracy and effectiveness literature with economic modeling. Health Technol Asses. 2008; 12: 1270.

9. Yankowitz J. Pharmacologic treatment of hypertensive disorders during pregnancy. J Perinat Neonat Nurs. 2004; 18: $230-40$.

10. National High blood pressure education program. Working Group Report in High Blood Pressure in Pregnancy. Betheseda, MD: National Institutes of Health; 2000. (NIH Publication, N.00-3029).

11. Pritchard JA, Cunningham FG, Pritchard AS. The Parkland Memorial Hospital protocol for treatment of eclampsia: evaluation of 254 cases. Am J Obstet Ginecol. 1984; 148: 951-63.

12. Sibai BM. Diagnosis, prevention, and management of eclampsia. Obstet Gynecol. 2005; 105: 402-10.

13. Stata: Data analysis and statistical software [base de dados na Internet]. Texas (US): StataCorp. C1996-2008. Available in: http://www.stata.com [2008 Oct 17].

14. Parpinelli MA, Surita FGC, Pereira BC, Cecatti JG, Silva JLP, Boava RS. Fatores associados à eclâmpsia em gestantes com hipertensão arterial. Rev Bras Ginecol Obstet. 1996; 18: 705-12.

Recebido em 6 de julho de 2009

Versão final apresentada em 30 de outubro de 2009

Aprovado em 11 de março de 2010
15. Oliveira CA, Lins CP, Sá RAM, Netto HC, Bornia RG, Silva NR, Amin Jr J. Síndromes hipertensivas da gestação e repercussões perinatais. Rev Bras Saúde Mater Infant. 2006; 6: 93-8.

16. Cavalli RC, Sandrim VC, Santos JET, Duarte G. Predição de pré-eclâmpsia. Rev Bras Ginecol Obstet. 2009; 31: 1-4.

17. Bezerra EHM, Alencar Jr. CA, Feitosa RFG, Carvalho AAA. Mortalidade materna por hipertensão: índice e análise de suas características em uma maternidade escola. Rev Bras Ginecol Obstet. 2005; 27: 548-53.

18. Santillo H, Carvalho GC, Alves DSN, Neumann ZA, Formiga Filho JNF. Manual dos Comitês de Mortalidade Materna. Ministério da Saúde, Secretaria da Assistência à Saúde. Brasília, DF: Ministério da Saúde; 1994.

19. Tanaka M, Jaama G, Kaiser M, Hills E, Soim A, Zhu M, Shcherbatykh IY, Samelson R, Bell E, Zdeb M, McNutt L A. Racial disparity in hypertensive disorders of pregnancy in New York State: a 10-year longitudinal population-based study. Am J Public Health. 2007; 97: 163-70.

20. Loureiro R, Leite CC, Kahhale S, Freire S, Sousa B, Cardoso EF, Alves EA, Borba P, Cerri GG, Zugaib M. Diffusion imaging may predict reversible brain lesions in eclâmpsia and sever preeclâmpsia: initial experience. Am J Obstet Gynecol. 2003; 189: 1350-5.

21. Duley L, Henderson-Smart D. Magnesium sulphate versus phenytoin for eclampsia. Cochrane Database Syst Rev. 2008; (4): CD000128.

22. Duley L, Gülmesoglu AM, Henderson-Smart DJ. Magnesium sulphate and other anticonvulsants for women with pre-eclampsia. Cochrane Database Syst Rev. 2008; (4): CD000025.

23. Souza ASR, Amorim MMR, Santos RE, Noronha Neto C, Porto AMF. Efeito do sulfato de magnésio sobre o índice das artérias uterinas, umbilical e cerebral média fetal de acordo com a persistência da incisura protodiastólica da artéria uterina na pré-eclâmpsia grave. Rev Bras Ginecol Obstet. 2009; 31: 82-8.

24. Silva JLP, Cecatti JG, Serruya SJ. A qualidade do pré-natal no Brasil. Rev Bras Ginecol Obstet. 2005; 27: 103-5.

25. Mayi-Tsonga S, Alonso L, Ngou-Mve-Ngou JP, Meye JF. Facteurs de risque de l'éclampsie à Libreville (Gabon): étude cas-térmoins. Sancte. 2006; 16: 197-20.

26. Barbosa AS, Boyaciyan K, Marcus PAF, Veja CEP. Dificuldades encontradas para o estudo de casos de mortalidade materna na cidade de São Paulo (de 1993 a 1995). Rev Bras Ginec Obstet. 1997; 19: 179-83.

27. Aguiar RALP, Rezende CAL, Cabral ACV, Asseury S, Perrupato R. Mortalidade materna no Hospital das Clínicas da UFMG: uma análise retrospectiva de 6 anos. Rev Bras Ginecol Obstet. 1991; 13: 224-7. 